\title{
2018 in review: gynecologic cancer insights
}

\author{
2018 em revisão: insights sobre câncer ginecológico
}

Eduardo Paulino $1,2,3$, Aknar F.C. Calabrich ${ }^{1,4}$, Andrea P.G. Guimarães ${ }^{1,8}$, Andreia C. Melo ${ }^{1,2,3}$, Daniela Freitas ${ }^{1,6,7}$, Fernando C. Maluf ${ }^{1,9,10}$, Lilian D. Faroni ${ }^{1,5}$, Marcelo A. Vieira ${ }^{1,12}$, Reitan Ribeiro ${ }^{1,11}$, Angelica Nogueira-Rodrigues ${ }^{1,13,14}$

\begin{abstract}
Gynecologic cancers constitute an important burden of disease around the world. Estimates from GLOBOCAN 2018 reveals approximately 1,247,300 incident casesand 596,000 related deaths of cancers of the uterine cervix, corpus uteri, and ovarian, annually around the world. In 2018 lots of promising results to improve disease control have been presented at international gynecological cancer meetings. The current review highlights some of the top gynecologic cancer news of 2018, including the new standard of care for BRCAmutant ovarian cancer patients with maintenance olaparib in first line, benefit of bevacizumab rechallenge for relapsed ovarian cancer patients, and the unexpected results of worse overall survival with minimally invasive surgery in early cervical cancer, among others.
\end{abstract}

Keywords: Gynecologic cancer, review, 2018.

1. Grupo Brasileiro de Tumores Ginecológicos, Grupo EVA - Belo Horizonte - MG - Brazil.

2. Instituto Nacional de Câncer, Medical Oncology - Rio de Janeiro - RJ - Brazil.

3. Grupo Oncoclínicas, Medical Oncology - Rio de Janeiro - RJ - Brazil.

4. Clínica AMO, Medical Oncology - Salvador - BA - Brazil.

5. Américas Centro de Oncologia Integrado, Radiation Oncology - Rio de Janeiro - RJ - Brazil.

6. Instituto do Câncer do Estado de São Paulo, Medical Oncology - São Paulo - SP - Brazil.

7. Hospital Sírio Libanês, Medical Oncology - São Paulo - SP - Brazil.

8. AC Camargo Cancer Center, Medical Oncology - São Paulo - SP - Brazil.

9. Beneficência Portuguesa, Medical Oncology - São Paulo - SP - Brazil.

10. Hospital Albert Einstein, Medical Oncology - São Paulo - SP - Brazil.

11. Hospital Erasto Gartner, Gynecologic Oncology - Curitiba - PR - Brazil.

12. Barretos Cancer Hospital, Gynecologic Oncology - Barretos - SP - Brazil.

13. DOM Oncologia, Medical Oncology - Divinópolis - MG - Brazil.

14. Universidade Federal de Minas Gerais, Medical Oncology - Belo Horizonte - MG - Brazil.

Financial support: none to declare.

Conflicts of interest: No Conflict of interest.

Correspondence author: Angelica Nogueira-Rodrigues. Departamento de Clínica Médica, Faculdade de Medicina UFMG.

Av. Prof. Alfredo Balena, 190 - Santa Efigênia, Belo Horizonte - MG, 30130-100.

E-mail: angelica.onco@uol.com.br.

Received on: December 25, 2018 | Accepted on: December 26, 2018

DOI: $10.5935 / 1806-6054.20190008$ 


\begin{abstract}
RESUMO
Os tumores ginecológicos constituem um verdadeiro fardo à saúde feminina mundialmente. Estimativas do GLOBOCAN 2018 demonstram cerca de 1.247.300 casos e 596.000 mortes anualmente relacionadas aos tumores ginecológicos. Em 2018 foram apresentados trabalhos importantes sobre o manejo destes tumores nos principais congressos internacionais. Esse artigo de revisão destaca alguns destes trabalhos como a manutenção de olaparibe em primeira linha para as pacientes com câncer de ovário e mutação de $B R C A$, o benefício da re-exposição ao bevacizumabe para pacientes com câncer de ovário recidivado (platino sensível), os resultados inesperados da cirurgia minimamente invasiva em câncer de colo uterino inicial, dentre outros.
\end{abstract}

Descritores: Neoplasias Genitais Femininas. Revisão.

\section{INTRODUCTION}

Gynecological oncology was the focus of great advances in 2018. Some standards of care have been affected, such as in ovarian and cervical cancer. In cervical cancer, the awaited LACC trial has been presented, and its unexpected results raises questions on the safety of minimally invasive surgery (MIS). In ovarian cancer, SOLO1 trial recasts treatment for BRCA pathogenic variant carriers, MITO-MANGO shows benefit of bevacizumab rechallenge for relapsed patients and, GOG 213, on the opposite way of DESKTOP III trial, brings uncertainty on the role of secondary surgery. This year's review is a snapshot of the year, condensing selected gynecologic cancer trials that can affect clinical practice (Table 1).

\section{CERVICAL CANCER: A NEW ERA AFTER THE LACC TRIAL}

LACC trial, the first randomized controlled trial comparing MIS, laparoscopy or robotic, versus open surgery for patients with initial cervical cancer have been just published. The unexpected results immediately alerted the oncology community as nobody was expecting that MIS would have worse disease free survival (DFS) and overall survival (OS)(1).

Patients included should have FIGO stage IA1 (lymphovascular invasion) to IB1, squamous cell, adenocarcinoma or adenosquamous histology; 312 patients had been randomized to open radical hysterectomy and 319 patients to MIS (83\% laparoscopy and $16 \%$ robotic surgery). The majority ( $92 \%$ in both) harbored stage IB1 disease. In the open surgery group, $88 \%$ received randomized treatment versus $91 \%$ in the minimally invasive surgery group. The conversion rate to laparotomy was 3\%. At the time of analysis, information available at 4.5 years was $60 \%$, with over $80 \%$ power for the primary endpoint and median follow-up of 2.5 years. The non-inferiority boundary of $-7.2 \%$ for disease-free survival at 4.5 years was breached (open 97\% versus minimally invasive surgery $86 \%$, difference $-10.6 \%$, $95 \% \mathrm{Cl}-16.4 \%$ to $-4.7 \%$, difference not significant).
MIS was found to be associated with over a 3-fold increase in disease-free survival (7 of 312 versus 27 of 319 , hazard ratio $3.74,95 \% \mathrm{Cl} 1.63-8.58, \mathrm{p}=0.002$ ). This finding was consistent when adjusted for age, body mass index, stage of disease, lymphovascular space involvement, lymph node involvement, and performance status. MIS was also associated with a decrease in overall survival (3 of 312 versus 19 of 319 , hazard ratio $6.00,95 \% \mathrm{Cl} 1.48-20.3, p=0.004$ ). Rates of intraoperative complications did not differ by treatment received (11\% in both) (Table 1).

Some limitations have to be mentioned about the study: first, the results of open arm were much better than expected, giving the impression that the results from the MIS arm were even worse. Second, the recruitment was suspended after achieving around $90 \%$ of the expected number of patients because of the evident worse result of one of the arms (MIS).

In the end, as always, new studies will prove or not these results.

\section{OVARIAN CANCER: NEW STANDARD OF CARE IN FRONT LINE SETTING AND OTHER OPTIONS IN PLATINUM SENSITIVE RECURRENT DISEASE}

\section{SOL01}

The phase III study SOLO-1 evaluated the role of olaparib, a PARP inhibitor, as maintenance therapy in patients with newly diagnosed advanced (FIGO III or IV) high- grade serous or endometrioid ovarian cancer, primary peritoneal cancer, or fallopian-tube cancer with a mutation in $B R C A 1, B R C A 2$, or both. Three hundred and ninety-one patients who had complete or partial response after first-line platinum-based chemotherapy were randomized (2:1) to receive olaparib $300 \mathrm{mg}$ twice daily or placebo for 2 years. Patients who underwent initial or interval surgery (36\%) were included, and 18\% of them had not achieved complete response after platinum-based treatment. The initiation of maintenance should be between four and eight weeks after the end of chemotherapy. 


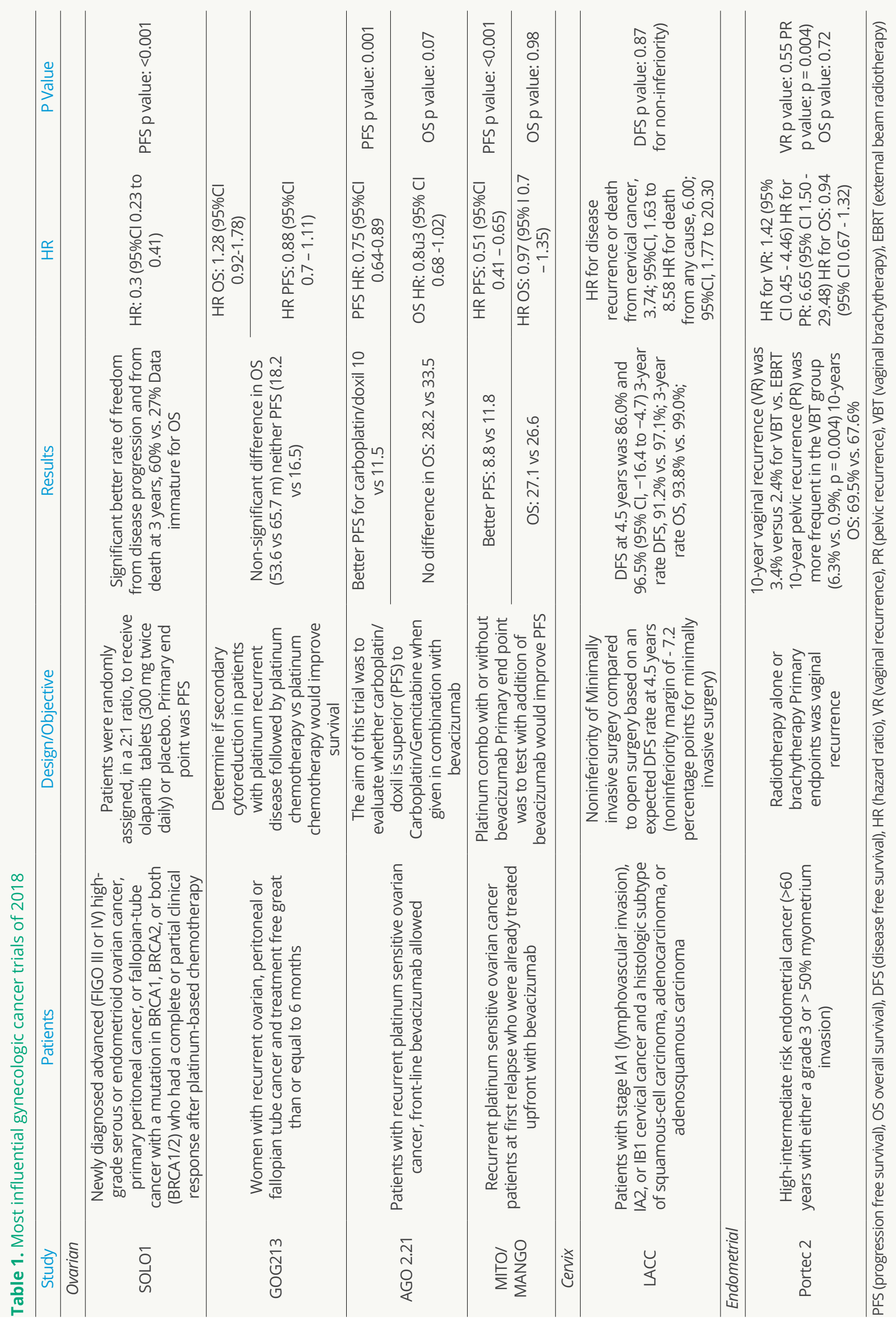


There was a significant increase in progression-free survival (PFS), which was the primary endpoint (13.8 months for the placebo group versus a median time not achieved in the olaparib group). With a median follow-up of 41 months, the estimated rate of freedom from progression or from death at 3 years was $70 \%$ lower in the olaparib group $(60 \%$ versus $27 \%$ in the placebo group, $\mathrm{HR} 0.30,95 \% \mathrm{Cl}$ $0.23-0,41, p<0.001)$, confirmed by central investigator. There was also an expressive increase in the secondary endpoint that was second PFS, median time not reached in the olaparib group versus 41.9 months in the placebo arm $(\mathrm{HR} 0.50,95 \% \mathrm{Cl} 0.35$ $0.72 ; p<0.001$ ).

The most commonly adverse events are consistent with toxic effects reported for PARP inhibitors such as gastrointestinal disorders (nausea, vomiting, and diarrhea), fatigue, and anemia. Serious adverse events occurred in $21 \%$ of the patients in the olaparib group versus $12 \%$ in the placebo group, and $12 \%$ of the patients in the olaparib group discontinued the treatment due to toxicity.

Olaparib maintenance therapy demonstrated significant benefit in PFS in BRCA mutated patients with newly diagnosed advanced ovarian epithelial cancer.

\section{MIT016B-MaNGOOV2B-ENGOTOV17}

Bevacizumab in combination to first-line carboplatin and paclitaxel and as maintenance prolongs PFS in patients with stage IIIB-IV OC. It is also approved in bevacizumab-naive patients with platinum sensitive or resistant relapse. At ASCO 2018, it was presented a randomized, open label, phase III trial to test if the addition of bevacizumab to a platinum-based chemotherapy prolongs PFS for recurrent platinum sensitive ovarian cancer patients who have received bevacizumab in first line treatment ${ }^{(2)}$. They were randomized to 6 cycles of platinum-based doublets (carboplatin/paclitaxel, carboplatin/gemcitabine or carboplatin/pegylated liposomal doxorubicin) with or without bevacizum$\mathrm{ab}$ administered concomitant with chemotherapy and as maintenance until disease progression. Four hundred and five patients were enrolled; $64 \%$ of patients had progressed $\geq 12$ months after the last dose of platinum and $72 \%$ of patients after completion of first-line bevacizumab maintenance. Median PFS was 8.8 months and 11.8 months without and with bevacizumab, respectively (HR 0.51, $95 \% \mathrm{Cl}$ 0.41-0.64, $\mathrm{p}<0.001$ ); median OS was 27.1 months and 26.7 months without and with bevacizumab, respectively ( $\mathrm{HR} 1.00,95 \% \mathrm{Cl}$ 0.73-1.39, $\mathrm{p}=0.98$ ) (Table 1). Severe (grade 3 or 4 ) hypertension $(27.5 \%$ versus $9.7 \%, p<0.001)$ and proteinuria ( $4 \%$ versus $0 \%, p=0.007$ ) were more frequent in the bevacizumab arm. This trial shows that patients with platinum sensitive recurrent OC previously treated with bevacizumab in first line setting can be rechallenge with bevacizumab in combination with platinum-based doublets with no unexpected toxicity.

\section{AGO-OVAR 2.21/ENGOT-ov 18 trial}

Presented at ESMO 2018, this is the first prospective, randomized, phase III trial comparing two schemes containing bevacizumab in patients with platinum-sensitive recurrent ovarian cancer ${ }^{(3)}$. It is known that carboplatin/gemcitabine/bevacizumab significantly increases PFS over carboplatin/gemcitabine alone whilst carboplatin/pegylated liposomal doxorubicin has better toxicity profile compared to carboplatin/paclitaxel in patients with platinum-sensitive recurrent ovarian cancer. The aim of this trial was to evaluate whether carboplatin/pegylated liposomal doxorubicin is superior to carboplatin/ gemcitabine when given in combination with bevacizumab. Primary endpoint was PFS and secondary endpoints were OS, biological progression- free survival by serum CA125, quality of life, safety and tolerability. Between 2013 and 2015, 682 patients were randomized to carboplatin/gemcitabine/bevacizumab ( $n=337$, standard arm, CGB) or carboplatin/pegylated liposomal doxorubicin/bevacizumab $(n=345$, experimental arm, CDB). Prior bevacizumab was allowed. At data cut-off, 571 events occurred, CGB was associated with 359 (53.3\%) serious adverse events versus $314(46.7 \%)$ for CDB $(p=0.083)$. Median PFS in the standard arm was 11.7 months (95\% Cl 11.1-12.8) versus 13.3 months $(95 \% \mathrm{Cl} 11.7-$ 14.3) in the experimental arm (HR $0.80 ; 95 \% \mathrm{Cl} 0.68$ $0.96, p=0.0128)$. In the stratum with previous anti-angiogenic treatment $(n=309)$ median PFS was 10.1 months versus 11.3 months, respectively (HR 0.73; $95 \% \mathrm{Cl}$ 0.57-0.94, $\mathrm{p}=0.0126$ ) (Table 1). CDB provided a significant PFS improvement compared to CGB in patients with platinum-sensitive recurrent ovarian cancer with fewer serious adverse events. Thus, this schema might be an important therapeutic option in this scenario. Future studies should compare other platinum doublets in combination with bevacizumab, including carboplatin and paclitaxel.

\section{GOG 213 - Secondary Cytoreductive Surgery}

Patients with limited platinum-sensitive recurrent ovarian cancer (PSOC) have secondary cytoreductive surgery (SCS) as an optional approach that should be considered. In 2017, the interim analysis of the DESKTOP III presented at the ASCO meeting supported this strategy ${ }^{(4)}$. However, this year during the ASCO meeting, the presentation of the second objective of the GOG213 gave a different perspective for the SCS ${ }^{(5)}$. This study was design with two primary objectives: first to evaluate the addition of bevacizumab to the traditional carboplatin/paclitaxel in patients with PSOC (these results were published last year) ${ }^{(6)}$ and second to determine if SCS followed by chemotherapy would improve OS of those patients. Exploratory objectives included access the effect of secondary surgery on platinum-free survival. To be included in the trial the patients must have had complete response to front-line therapy including: complete clinical, radiologic and CA125 responses; platinum-free interval $>/=6$ months; and clinically evident recurrence confirmed by biopsy and measurable. 
From December 2007 until June 2017, 485 women were randomized to have SCS followed by platinum based chemotherapy (PBC) or PBC alone. The goal of the SCS was complete removal of all visible disease (RO) and $68 \%$ of the patients who underwent surgery achieved this goal. With a median follow-up of 34.6 months, there was no significant difference in OS between the two arms. The median OS was 53.6 months to the SCS group versus 65.7 months in the group treated exclusively with PBC (Table 1). Apparently, the addition of bevacizumab ( $84 \%$ of the patients) to the PBC has overcome the benefit of the SCS for those patients. The authors concluded that SCS with PBC was not associated with OS improvement when compared to chemotherapy alone.

\section{Endometrial carcinoma: efficacy based in sub- groups of the PORTEC 2 trial}

Relatively few clinically important therapeutic advances have occurred in the treatment of endometrial cancer. PORTEC 2 is one of the most important trial on this subject and has been updated with 10year follow-up. This was a randomized clinical trial in high-intermediate risk (HIR) endometrial cancer (>60 years with either a grade 3 or $>50 \%$ myometrium invasion) comparing eternal beam radiotherapy (EBRT) with vaginal brachytherapy (VB). They evaluated long-term outcomes combined with pathology review and molecular analysis. Four hundred forty seven women with HIR endometrial cancer were randomized between 2000-2006 to VB or EBRT. Exclusion criteria were serous or clear cell carcinoma; staging lymphadenectomy; >8 weeks interval between surgery and radiotherapy; history of previous malignance; previous pelvic radiotherapy, hormonal and chemotherapy; Crohn's disease or ulcerative colitis. Primary endpoint was vaginal recurrence (VR). With a median follow up of 116 months, 10 year VR was $3.4 \%$ versus $2.4 \%$ for VB vs. EBRT $(p=0.55) ; 10$ year pelvic recurrence (PR) was more frequent in VB group (6.3 versus $0.9 \% p=0.004)$, mostly combined with distant metastasis (DM). Ten- year isolated PR was 2.5 versus $0.5 \%(p=0.1)$ and DM 10.4 versus $8.9 \%(p=0.45)$. OS for VB versus EBRT was 69.5 versus $67.6 \%(p=0.72)$ (Table 1$)$. L1CAM or p53 mutant expression and substantial lymph-vascular space invasion were risk factors for PR and DM, favoring EBRT in these cases. Ten-year long-term of PORTEC 2 confirm VB as standard adjuvant treatment for HIR endometrial cancer. Patients with either lymph- vascular invasion, L1CAM or p53 expression should be futher evaluated in a prospective clinical trial before being used as standard for choosing between adjuvant EBRT or VB.

\section{REFERENCES}

1. Ramirez PT, Frumovitz M, Pareja R, Lopez A, Vieira $M$, Ribeiro $R$, et al. Minimally Invasive versus Abdominal Radical Hysterectomy for Cervical Cancer. N Engl J Med. 2018;379(20):1895-904. DOI: 10.1056/NEJMoa1806395

2. Pignata S, Lorusso D, Joly F, Gallo C, Colombo $N$, Sessa $S$, et al. Chemotherapy plus or minus bevacizumab for platinum-sensitive ovarian cancer patients recurring after a bevacizumab containing first line treatment: The randomized phase 3 trial MITO16B-MaNGO OV2B-ENGOT OV17. J Clin Oncol. 2018;36(15 Suppl):5506.

3. Pfisterer J, Dean AP, Baumann K, Rau J, Harter P, Joly $\mathrm{F}$, et al. Carboplatin/pegylated liposomal doxorubicin/bevacizumab (CD-BEV) vs. carboplatin/gemcitabine/bevacizumab (CG-BEV) in patients with recurrent ovarian cancer: A prospective randomized phase III ENGOT/GCIG-Intergroup study (AGO study group, AGO-Austria, ANZGOG, GINECO, SGCTG). Ann Oncol. 2018;29(Suppl 8):viii332-viii358. DOI: 10.1093/annonc/mdy285.142

4. Du Bois A, Vergote I, Ferron G, Reuss A, Meier W, Greggi S, et al. Randomized controlled phase III study evaluating the impact of secondary cytoreductive surgery in recurrent ovarian cancer: AGO DESKTOP III/ENGOT ov20.J Clin Oncol. 2017;35(15 Suppl):5501.

5. Coleman RL, Enserro D, Spirtos N, Herzog TJ, Sabbatini $\mathrm{P}$, Armstrong DK, et al. A phase III randomized controlled trial of secondary surgical cytoreduction (SSC) followed by platinum-based combination chemotherapy (PBC), with or without bevacizumab (B) in platinum-sensitive, recurrent ovarian cancer (PSOC): A NRG Oncology/Gynecologic Oncology Group (GOG) study. J Clin Oncol. 2018;36(15 Suppl):5501. DOI: 10.1200/JCO.2018.36.15_suppl.5501

6. Coleman RL, Brady MF, Herzog TJ, Sabbatini P, Armstrong DK, Walker JL, et al. Bevacizumab and paclitaxel-carboplatin chemotherapy and secondary cytoreduction in recurrent, platinum-sensitive ovarian cancer (NRG Oncology/Gynecologic Oncology Group study GOG-0213): a multicentre, open-label, randomised, phase 3 trial. Lancet Oncol. 2017;18(6):77991. DOI: $10.1016 /$ S1470-2045(17)30279-6

7. Wortman BG, Creutzberg CL, Putter $\mathrm{H}$, JürgenliemkSchulz IM, Jobsen JJ, Lutgens LCHW, et al.; PORTEC Study Group. Ten-year results of the PORTEC-2 trial for high-intermediate risk endometrial carcinoma: improving patient selection for adjuvant therapy. Br J Cancer. 2018;119(9):1067-74. DOI: 10.1038/ s41416-018-0310-8 